\title{
Enhancement and modeling of enzymatic hydrolysis on cellulose from agave bagasse hydrothermally pretreated in a horizontal bioreactor
}

\author{
Marcela Sofía Pino ${ }^{\text {a }}$, Rosa M. Rodríguez-Jasso ${ }^{\mathrm{a}, \mathrm{b}}$, Michele Michelin ${ }^{\mathrm{c}}$, Héctor A. Ruiz ${ }^{\mathrm{a}, \mathrm{b}, *}$ \\ ${ }^{a}$ Biorefinery Group, Food Research Department, Faculty of Chemistry Sciences, Autonomous University of Coahuila, Saltillo, Coahuila 25280, Mexico \\ ${ }^{\mathrm{b}}$ Cluster of Bioalcohols, Mexican Centre for Innovation in Bioenergy (Cemie-Bio), Mexico \\ ${ }^{\mathrm{c}}$ Centre of Biological Engineering, University of Minho, Campus Gualtar, 4710-057 Braga, Portugal
}

\section{A R T I C L E I N F O}

\section{Keywords:}

Glucan

Glucose

Biofuels

Autohydrolysis

Severity factor

Biorefinery

\begin{abstract}
A B S T R A C T
One of the major challenges in biofuels production from lignocellulosic biomass is the generation of high glucose titers from cellulose in the enzymatic hydrolysis stage of pretreated biomass to guarantee a cost-effective process. Therefore, the enzymatic saccharification on cellulose at high solid loading is an alternative. In this work, the agave bagasse was hydrothermally pretreated and optimized at $194^{\circ} \mathrm{C} / 30 \mathrm{~min}$, obtaining a pretreated solid rich in cellulose content ( $>46.46 \%$ ), and subjected to enzymatic hydrolysis at high solid levels. A horizontal bioreactor was designed for enzyme saccharification at high solid loadings [25\% (w/v)]. The bioreactor improved mixing efficiency, with cellulose conversions up to $98 \%(195.6 \mathrm{~g} / \mathrm{L}$ at $72 \mathrm{~h})$. Moreover, mathematical modeling of cellulase deactivation demonstrated that cellulases lose most of their initial activity in the first hours of the reaction. Also, cellulose was characterized by X-ray diffraction, and the pretreated solids were visualized using scanning electron microscopy.
\end{abstract}

\section{Introduction}

Second-generation bioethanol has gained interest as a renewable alternative to fossil fuels (Wyman, Cai, \& Kumar, 2019). It is produced from lignocellulosic materials, such as agave bagasse (AGB), the residue left from the tequila production, mainly composed by cellulose, hemicellulose and lignin (Caspeta, Caro-Bermúdez, Ponce-Noyola, \& Martinez, 2014). In Mexico, the Tequila Regulatory Council (www.crt. org.mx) reported a consumption of agave for tequila production of 956.1 thousand tons in 2017, which represents approximately 382.44 thousand tons of agave bagasse generated ( $40 \%$ of the processed agave on dry basis) (Davis, Dohleman, \& Long, 2011).

Bioethanol production from lignocellulosic biomasses entails four main stages: pretreatment, enzymatic hydrolysis, and fermentation followed by distillation. The pretreatment is an essential step because it modifies the structure of the material. Hydrothermal pretreatment (HT), also known as autohydrolysis, is an eco-friendly pretreatment method that consists on the subjection of the raw material to high temperature and pressure in an aqueous medium, which causes the solubilization of hemicellulose and promotes the digestibility of cellulose. Furthermore, hydrothermal pretreatment induces the relocation of lignin in the biomass, favoring cellulose accessibility (Ruiz, Rodríguez-
Jasso, Fernandes, Vicente, \& Teixeira, 2013; Ruiz, Thomsen, \& Trajano, 2017). After the pretreatment, an enzymatic hydrolysis (EH) is carried out to produce fermentable sugars for the downstream processes. $\mathrm{EH}$ is a heterogeneous reaction in which cellulase enzymes are used to depolymerize cellulose (glucan) into monomeric sugars. Cellulases are specific enzymes mainly conformed by endo- $\beta-1,4$-glucanase, exo- $\beta$ 1,4-cellobiohydrolase and 1,4- $\beta$-glucosidases, which act synergistically to hydrolyze cellulose into glucose (Ruiz, Vicente, \& Teixeira, 2012). However, during the $\mathrm{EH}$, the presence of a wide range of compounds restrict the action of cellulase enzymes, including hemicellulose, phenolic compounds, acetyl groups and lignin, which act as physical barriers for the cellulases action. Also, lignin presence may cause cellulases deactivation, due to non-productive adsorption of the enzymes into lignin's surface (Pino et al., 2018). Moreover, it has been demonstrated that cellulases experience feedback inhibition by glucose and cellobiose (Andrić, Meyer, Jensen, \& Dam-Johansen, 2010).

Lately, several alternatives have been proposed to improve cellulose conversion. One of them is the implementation of high solid loadings (above $15 \% \mathrm{w} / \mathrm{w}$ ) to guarantee a cost-effective production process (Caspeta, 2014; Chen \& Liu, 2016), which represent some advantages, such as higher glucose concentration, reduced operating costs, and lower water consumption (Chen \& Liu, 2016). However, at high solid

\footnotetext{
* Corresponding author at: Biorefinery Group, Food Research Department, Faculty of Chemistry Sciences, Autonomous University of Coahuila, Saltillo, Coahuila 25280, Mexico.

E-mail address: hector_ruiz_leza@uadec.edu.mx (H.A. Ruiz).
} 
Table 1

Experimental conditions evaluated in the autohydrolysis pretreatment. Severity factor, $\mathrm{pH}$ and heating rate for the pretreatment assays.

\begin{tabular}{|c|c|c|c|c|c|c|c|c|c|}
\hline \multirow{2}{*}{$\begin{array}{l}\text { Temperature }\left({ }^{\circ} \mathrm{C}\right) \\
\text { Time (min) }\end{array}$} & \multicolumn{3}{|l|}{$160^{\circ} \mathrm{C}$} & \multicolumn{3}{|l|}{$190^{\circ} \mathrm{C}$} & \multicolumn{3}{|l|}{$220^{\circ} \mathrm{C}$} \\
\hline & 10 & 30 & 50 & 10 & 30 & 50 & 10 & 30 & 50 \\
\hline$\left[\log R_{0}\right]$ & 3.56 & 3.90 & 4.06 & 3.73 & 4.00 & 4.16 & 3.89 & 4.14 & 4.28 \\
\hline $\mathrm{pH}$ & 4.08 & 4.05 & 3.98 & 3.77 & 3.59 & 3.55 & 3.47 & 3.49 & 3.60 \\
\hline Heating rate $\left({ }^{\circ} \mathrm{C} / \mathrm{min}\right)$ & 6.33 & 6.59 & 7.07 & 5.86 & 5.85 & 5.89 & 5.29 & 4.76 & 4.37 \\
\hline \multicolumn{10}{|c|}{ Solid phase composition (\% on total dry weight) } \\
\hline Cellulose & $27.31 \pm 0.42$ & $31.34 \pm 0.33$ & $35.36 \pm 0.89$ & $38.26 \pm 1.04$ & $42.58 \pm 0.63$ & $42.93 \pm 0.98$ & $40.58 \pm 0.22$ & $37.12 \pm 0.15$ & $31.99 \pm 0.87$ \\
\hline Hemicellulose & $5.67 \pm 0.17$ & $6.02 \pm 0.13$ & $6.23 \pm 0.34$ & $0.00 \pm 0.00$ & $0.00 \pm 0.00$ & $0.00 \pm 0.00$ & $0.00 \pm 0.00$ & $0.00 \pm 0.00$ & $0.00 \pm 0.00$ \\
\hline Lignin & $17.77 \pm 0.36$ & $23.99 \pm 0.20$ & $25.22 \pm 0.17$ & $26.89 \pm 0.70$ & $32.16 \pm 0.63$ & $35.70 \pm 1.30$ & $35.84 \pm 0.12$ & $41.71 \pm 0.56$ & $42.95 \pm 0.46$ \\
\hline \multicolumn{10}{|c|}{ Liquid phase composition (g/L) } \\
\hline Glucose & $0.06 \pm 0.002$ & $0.27 \pm 0.000$ & $0.41 \pm 0.002$ & $0.00 \pm 0.000$ & $0.00 \pm 0.000$ & $0.00 \pm 0.000$ & $0.00 \pm 0.000$ & $0.00 \pm 0.000$ & $0.00 \pm 0.000$ \\
\hline Xylose & $3.71 \pm 0.008$ & $2.97 \pm 0.000$ & $2.60 \pm 0.005$ & $1.38 \pm 0.001$ & $2.03 \pm 0.010$ & $1.30 \pm 0.016$ & $0.21 \pm 0.003$ & $0.00 \pm 0.000$ & $0.00 \pm 0.000$ \\
\hline Arabinose & $0.03 \pm 0.004$ & $0.42 \pm 0.001$ & $0.35 \pm 0.007$ & $0.19 \pm 0.002$ & $0.00 \pm 0.000$ & $0.00 \pm 0.000$ & $0.00 \pm 0.000$ & $0.00 \pm 0.000$ & $0.00 \pm 0.000$ \\
\hline XOS & $0.82 \pm 0.002$ & $2.79 \pm 0.082$ & $4.31 \pm 0.004$ & $8.37 \pm 0.118$ & $3.53 \pm 0.079$ & $0.00 \pm 0.000$ & $0.00 \pm 0.000$ & $0.00 \pm 0.000$ & $0.00 \pm 0.000$ \\
\hline Acetic acid & $0.41 \pm 0.002$ & $0.84 \pm 0.003$ & $1.19 \pm 0.003$ & $2.01 \pm 0.007$ & $3.87 \pm 0.010$ & $4.98 \pm 0.002$ & $4.78 \pm 0.002$ & $5.52 \pm 0.005$ & $5.17 \pm 0.004$ \\
\hline Furfural & $0.02 \pm 0.004$ & $0.08 \pm 0.001$ & $0.14 \pm 0.001$ & $0.51 \pm 0.001$ & $1.72 \pm 0.006$ & $2.49 \pm 0.013$ & $1.84 \pm 0.006$ & $1.24 \pm 0.012$ & $0.85 \pm 0.008$ \\
\hline HMF & $0.00 \pm 0.000$ & $0.25 \pm 0.001$ & $0.32 \pm 0.002$ & $0.46 \pm 0.001$ & $0.69 \pm 0.007$ & $0.78 \pm 0.017$ & $0.99 \pm 0.000$ & $0.77 \pm 0.001$ & $0.58 \pm 0.001$ \\
\hline Formic acid & $0.68 \pm 0.002$ & $0.72 \pm 0.000$ & $0.70 \pm 0.009$ & $1.01 \pm 0.001$ & $1.32 \pm 0.004$ & $1.48 \pm 0.001$ & $1.46 \pm 0.004$ & $1.45 \pm 0.001$ & $1.31 \pm 0.001$ \\
\hline Levulinic acid & $0.00 \pm 0.000$ & $0.00 \pm 0.000$ & $0.00 \pm 0.000$ & $0.01 \pm 0.000$ & $0.02 \pm 0.001$ & $0.00 \pm 0.000$ & $0.04 \pm 0.001$ & $0.94 \pm 0.004$ & $0.88 \pm 0.011$ \\
\hline
\end{tabular}

Xylooligosaccharides $=$ XOS.

loadings (cellulose), a highly viscous slurry is formed, which reduces the mixing efficiency and affect the substrate (cellulose)-enzyme (cellulase) interaction (Andrić et al., 2010; Du et al., 2014). Therefore, different bioreactor design strategies have been development to overcome mass transfer limitations at high solid loadings (Pino et al., 2018). Horizontal bioreactors have been stated as a promising alternative to enhance high solid loading enzymatic hydrolysis (Dasari, Dunaway, \& Berson, 2009; Du et al., 2014). Du et al. (2017) reported that, among different strategies, horizontal rotating bioreactors were the most effective alternative to assure an adequate mixing between solid substrate and enzyme in the EH performed at high solid loadings.

The present work aimed to study the enzymatic hydrolysis on cellulose from optimized agave bagasse hydrothermally pretreated using different solid loadings to evaluate substrate (cellulose) concentration effect on cellulose conversion yield; mathematical modeling of the saccharification of cellulose to glucose concentration was also conducted. Additionally, the cellulose before and after pretreatment was characterized; also a novel horizontal bioreactor was tested to improve enzymatic saccharification process.

\section{Materials and methods}

\subsection{Raw material}

Agave bagasse used in this investigation was kindly provided by a local tequila factory (Distillery Leyros, Tequila, Jalisco, Mexico). The AGB was initially characterized to determine the main constituents of the biomass for subsequent pretreatment and enzymatic hydrolysis assays performed in shake flasks and in the designed bioreactor. AGB was milled to a particle size between $0.5 \mathrm{~mm}$ and $1.0 \mathrm{~mm}$ using a Blade mill (Thomas Wiley, Swedesroro, NJ, USA). The raw material was subjected to moisture determination at $120^{\circ} \mathrm{C}$, ashes (Sluiter, Hames, et al., 2008) and solvent extractives (Sluiter, Ruiz, Scarlata, Sluiter, \& Templeton, 2008). Additionally, to physicochemically characterize the AGB, the content of the main polysaccharides was determined according to the standard analytical procedures of the National Renewable Energy Laboratory (NREL/TP-510-42618) (Sluiter et al., 2012), the monomeric sugars and acetic acid were analyzed by HPLC (see Section 2.4). Finally, the recovered solid was oven-dried and weighted to determine Klason lignin by gravimetric method.

\subsection{Hydrothermal pretreatment (autohydrolysis)}

Milled AGB and water were combined in a solid/liquid ratio of 1:10 $(\mathrm{w} / \mathrm{v})$. The mixture was hydrothermally pretreated with autohydrolysis process under an isothermal heating regimen with an agitation speed of 200 rpm via an anchor impeller in a stainless-steel Parr reactor with PID temperature controller (Series 4520, 1 L, Parr Instrument Company, USA). The operational conditions were selected according to typical values for hydrothermal pretreatment (Ruiz et al., 2017). The reactor was heated to the temperature established according to the experimental design and maintained for the specified residence time (see Section 2.2.1). Once the residence time was completed, the reactor was cooled down and the slurry obtained was filtrated to separate the solid from the liquid phase. The solid obtained was washed with distilled water to remove any residual hemicellulolytic phase. For the mass balances, the moisture content of the raw material was considered as water. The severity factor was used as a parameter to compare the assays carried out as described in Eqs. (1) and (2) (Chornet \& Overend, 2017; Overend, Chornet, \& Gascoigne, 1987).

$\log R_{0}=\left[R_{0}\right.$ Heating $]+\left[R_{0}\right.$ Isothermal process $]+\left[R_{0}\right.$ Cooling $]$

$$
\begin{aligned}
\log R_{0}= & {\left[\int_{0}^{t_{\text {máx }}} \frac{T(t)-100}{\omega}\right]+\left[\int_{c t r l}^{c t r f} \exp \left[\frac{T(t)-100}{\omega}\right] d t\right] } \\
& +\left[\int_{0}^{t_{\text {máx }}} \frac{T(t)-100}{\omega}\right]
\end{aligned}
$$

where $\left[\log R_{0}\right]$ is the severity factor, $t_{\text {máx }}(\min )$ is the time needed to achieve the maximum autohydrolysis temperature, $\operatorname{ctrl}$ and $\operatorname{ctrf}(\mathrm{min})$ are the times needed for the whole heating-cooling period, $T(t)$ and $T^{\prime}(t)$ $\left({ }^{\circ} \mathrm{C}\right)$ are the temperature profiles in heating and cooling, respectively, and $\omega$ is an empirical parameter with a value of 14.75 .

After the pretreatment, the solid phase was analyzed following the same method described for the raw material; while the hydrolysate was analyzed by HPLC. Furthermore, xylooligomers (XOS) were analyzed in the liquid phase by quantitative acid post-hydrolysis.

\subsubsection{Experimental design}

A central composite design with a $95 \%$ confidence level was used to identify the conditions that release the highest content of cellulose in the pretreated solid fraction. The conditions evaluated in the 
experimental assays are summarized in Table 1 . The central point was evaluated with 3 repetitions. The results obtained were analyzed using STATISTICA 8.0 software.

\subsubsection{Scanning electron microscopy}

The morphology modifications of the agave bagasse through the optimal and the most severe pretreatment conditions were evaluated by scanning electron microscopy analysis (SEM), which allowed to observe the surface of the cellulosic material. The images were observed using a SEM equipment Quanta 650 FEG, FEI, USA, with an accelerating voltage of $+3 \mathrm{kV}$ at different magnifications. The samples were mounted on sample holders with double-sided adhesive and sputtered with a $10 \mathrm{~nm}$ layer of gold.

\subsubsection{Crystallinity index}

The crystallinity index of the crude biomass, pretreated AGB at the optimal condition, and at the most severe condition $\left(220^{\circ} \mathrm{C}\right.$ for $\left.50 \mathrm{~min}\right)$ were determined by X-ray diffraction (XRD) analysis, using a PANalytical X'Pert PRO MRD X-Ray powder diffractometer System. The diffracted intensity was measured in a Bragg $2 \theta$ angle with a scanning range between $10^{\circ}$ and $50^{\circ}$ at a speed of $0.02^{\circ} / \mathrm{s}$. The radiation was generated by CuK $\alpha(\lambda=1.542 \AA)$. The crystallinity index was calculated according to Eq. (3) proposed by Segal, Creely, Martin, and Conrad (1959).

$C r I=\left[\frac{\left(I_{002}-I_{a m}\right)}{I_{002}}\right] \times 100$

where $C r I$ is the crystallinity index, $I_{002}$ is defined as the maximum intensity of the 002 peak $\left(2 \theta=22.5^{\circ}\right)$, and $I_{a m}$ denotes the amorphous fraction and is determined as the minimum among 200 and 110 peaks $\left(2 \theta=18^{\circ}\right)$. A high value of crystallinity index means that the material presents a high degree of order in the chains that conform it (Kaschuk \& Frollini, 2018).

\subsection{Enzymatic hydrolysis}

\subsubsection{Cellulase enzymes}

For the depolymerization of cellulose, commercial cellulase cocktail (Cellic Ctec2) from Trichoderma reesei was used, which was generously supplied by Novozymes, USA. Cellulase activity was measured according to the method established by the National Renewable Energy Laboratory (NREL/TP-510-42628) (Adney \& Nrel, 1996), obtaining an initial enzyme activity of $123 \mathrm{FPU} / \mathrm{mL}$.

\subsubsection{Enzymatic hydrolysis in shake flasks}

Hydrothermally pretreated AGB at the optimal condition $\left(194^{\circ} \mathrm{C}\right.$ for $30 \mathrm{~min}$ ) was used as substrate for the saccharification. Firstly, the enzymatic hydrolysis experiments were carried out in $50 \mathrm{~mL}$ shake flasks at $50{ }^{\circ} \mathrm{C}$ under $150 \mathrm{rpm}$ agitation for $72 \mathrm{~h}$ with enzyme loading of 15 FPU/g of glucan in $50 \mathrm{mM}$ citrate buffer to maintain the $\mathrm{pH}$ at 4.8 (Adney \& Nrel, 1996). To prevent microbial contamination, $0.2 \% \mathrm{w} / \mathrm{v}$ sodium azide was used as antimicrobial. Solid loadings of $1,10,15,20$, 25 and $30 \%(\mathrm{w} / \mathrm{v})$ were studied in a working volume of $25 \mathrm{~mL}$. The reaction was monitored at $3,6,9,12,24,48$ and $72 \mathrm{~h}$. The samples were centrifugated and the supernatant was analyzed by HPLC for sugar content (Ruiz et al., 2012). The experiments were performed by triplicate. Untreated agave bagasse was used as control. The saccharification yield was determined according to Eq. (4) (Dowe \& McMillan, 2008).

Saccharification yield $(\%)=\frac{[\text { Glucose }]+1.053[\text { Cellobiose }]}{1.111 f[\text { Biomass }]} \times 100$

where [Glucose] is glucose concentration $(\mathrm{g} / \mathrm{L})$, [Cellobiose] is cellobiose concentration $(\mathrm{g} / \mathrm{L})$, [Biomass $]$ is dry mass concentration at the beginning of the saccharification $(\mathrm{g} / \mathrm{L}), f$ is cellulose fraction in dry biomass $(\mathrm{g} / \mathrm{g}), 1.111$ is a factor to convert cellulose to equivalent glucose and, 1.053 is a factor to convert cellobiose to equivalent glucose.

2.3.2.1. Kinetic modeling of enzymatic hydrolysis. The results obtained from the enzymatic saccharification screening were fitted to the mathematical kinetic model proposed by Zhang, Xu, Xu, Yuan, and Guo (2010), using non-linear equation analysis in the commercial software POLYMATH 6.10. The model aims to study cellulase deactivation during EH process, which can be caused by different factors, including thermal, non-productive lignin binding and product inhibition. The model assumes that the substrate surface structure is homogeneous and that cellulases are a complex arrangement conformed by three main components that act synergistically to hydrolysate insoluble matter. The model describes glucose production considering cellulase deactivation as first and second order reaction, as presented in Eqs. (5) and (6), respectively.

$[P]=\left[S_{0}\right]\left\{1-\left[1-\frac{1-\exp \left(-k_{d e 1} t\right)}{1+\left(K_{e} /\left[E_{0}\right]\right)}\right]^{k 2 / k d e 1}\right\}$

$[P]=\left[S_{0}\right]\left\{1-\left[1+\frac{K_{e}\left[E_{0}\right]}{K_{e}+\left[E_{0}\right]} k_{d e 2} t\right]^{-k_{2} /\left(K_{e} k_{d e 2}\right)}\right\}$

where $[P]$ is the concentration of glucose $(g / L),\left[S_{0}\right]$ is the initial substrate concentration $(\mathrm{g} / \mathrm{L}),\left[E_{0}\right]$ is the initial enzyme concentration $(\mathrm{g} / \mathrm{L}), t$ is the reaction time $(\mathrm{h}), K_{e}$ is the equilibrium constant $(\mathrm{g} / \mathrm{L}), k_{2}$ is the product formation constant $\left(\mathrm{h}^{-1}\right), K_{d e 1}$ is the first order rate constant of cellulase deactivation $\left(\mathrm{h}^{-1}\right)$, and $K_{d e 2}$ is the second order rate constant of cellulase deactivation $(\mathrm{L} /(\mathrm{hg}))$.

\subsubsection{Horizontal Bioreactor operation for enzymatic hydrolysis at high solid loading}

A novel 2-L horizontal jacketed-stainless steel bioreactor with a pegmixer type impeller was designed for the development of enzymatic hydrolysis of lignocellulosic biomass at high solid loadings (design by biorefinery group: http://www.biorefinerygroup.com). The bioreactor designed is patent-pending, thus no further information about the specifications and dimensions is given.

2.3.3.1. Batch-mode in the horizontal bioreactor. After the screening hydrolysis assays in shake flasks, the enzymatic saccharification was studied in the constructed horizontal bioreactor using pretreated AGB at the optimal condition of pretreatment process $\left(194^{\circ} \mathrm{C}\right.$ for $\left.30 \mathrm{~min}\right)$, with substrate loadings of 25 and $30 \%(\mathrm{w} / \mathrm{v})$ insoluble matter in a working volume of $250 \mathrm{~mL}$. Enzymatic hydrolysis were carried out at $50{ }^{\circ} \mathrm{C}$ under $100 \mathrm{rpm}$ agitation, using cellulase cocktail Cellic Ctec 2 and citrate buffer ( $\mathrm{pH} 4.8)$ with $0.2 \%(\mathrm{w} / \mathrm{v})$ sodium azide as antimicrobial. The enzyme loading used was $15 \mathrm{FPU} / \mathrm{g}$ glucan. The reaction was monitored at $6,12,24,48$ and, $72 \mathrm{~h}$ to determine the concentration of sugars. The EH yield was calculated according to Eq. (4).

2.3.3.2. Fed-batch strategies in the horizontal bioreactor. Additionally, fed-batch strategies at high solid loadings were evaluated on the bioreactor as alternatives to rise substrate loading whilst maintaining low viscosity on the reaction medium with the aim to facilitate mass transfer between substrate-enzyme. Two fed-batch strategies were studied to enhance saccharification yields at a fixed final solid loading insoluble matter of $30 \%(w / v)$. First strategy in feed batchmode; substrate fed-batch was studied, starting with $20 \%(\mathrm{w} / \mathrm{v})$ solid loading and after $12 \mathrm{~h}$ of enzymatic reaction, addition of the remaining $10 \%(\mathrm{w} / \mathrm{v})$. The second strategy in feed batch-mode was carried out on enzyme and substrate fed-batch to prevent enzyme end-product inhibition. Initially, $20 \%(\mathrm{w} / \mathrm{v})$ solid loading was fed to the horizontal bioreactor with its respective amount of enzyme corresponding to $15 \mathrm{FPU} / \mathrm{g}$ glucan; elapsed $12 \mathrm{~h}$, the remaining substrate (additional 10\% (w/v)) and enzyme were added. 


\subsection{Analytical method}

The hydrolysates from pretreatment and enzymatic hydrolysis stage were filtered through a $0.45 \mu \mathrm{m}$ nylon filter and analyzed by a system of High-Performance Liquid Chromatography (HPLC) Agilent 1260 Infinity II with a refractive index for glucose, xylose, arabinose, acetic acid and degradation compounds using calibration curves of these pure compounds to determine their concentrations. A MetaCarb $87 \mathrm{H}$ column (300 $\mathrm{mm} \times 7.8 \mathrm{~mm}$, Agilent) was used for the analysis with a column temperature of $60^{\circ} \mathrm{C}$ and $0.005 \mathrm{~mol} / \mathrm{L}$ sulfuric acid as mobile phase, using a flow rate of $0.7 \mathrm{~mL} / \mathrm{min}$.

\section{Results and discussion}

\subsection{Composition of raw material}

The physicochemical composition obtained for the agave bagasse, used for enzymatic hydrolysis in shake flasks, on total dry weight was $20.85 \pm 1.25 \%$ cellulose (as glucan), $12.24 \pm 1.07 \%$ hemicellulose (as xylan and arabinan), $17.31 \pm 0.44 \%$ lignin, $8.36 \pm 0.58 \%$ water extractives, $1.53 \pm 0.10 \%$ acetone extractives, and $7.67 \pm 0.49 \%$ ashes. The polysaccharides composition of the AGB used for the saccharification experiments in the horizontal bioreactor designed was $25.67 \pm 0.71 \%$ cellulose (as glucan), $12.95 \pm 0.15 \%$ hemicellulose (as xylan and arabinan), and $19.88 \pm 0.47 \%$ lignin on total dry weight. The compositions obtained are similar to the previously reported by other authors for AGB, including Velázquez-Valadez, FaríasSánchez, Vargas-Santillán, and Castro-Montoya (2016), who reported concentrations of $26.81 \%$ cellulose, $13.33 \%$ hemicellulose, and $13.57 \%$ lignin. Also, Yang et al. (2015) obtained similar results with $26.0 \pm 1.2 \%$ cellulose, $22.8 \pm 1.2 \%$ hemicellulose, $13.8 \pm 1.3 \%$ lignin, and $6.0 \pm 0.1 \%$ ash.

\subsection{Hydrothermal pretreatment (autohydrolysis)}

Table 1 summarizes the experimental conditions evaluated in the hydrothermal pretreatment, as well as the results obtained for each of the assays developed, including the severity factor $\left[\log R_{0}\right]$, the $\mathrm{pH}$ of the liquid phase, the heating rate, and the solid and liquid phases composition. The $\mathrm{pH}$ value of the liquor presented a decreasing behavior with the increase of the severity of the pretreatment, due to the production of acidic degradation compounds, such as acetic acid, levulinic acid and formic acid, coming from the deacetylation of hemicellulose and the degradation of 5-hydroxymethylfurfural (HMF) and furfural. Zhang, Li, Huang, Yang, and Han (2018) found the same pH decreasing tendency with temperature increment on the pretreatment of corn stover by hydrothermal process. However, an exception was observed at $220^{\circ} \mathrm{C}$, with a slight increase in the $\mathrm{pH}$ due to the degradation of cellulose at temperatures higher than $200{ }^{\circ} \mathrm{C}$ that could lead to the formation of tars (mainly levoglucosan) and gaseous products from the pyrolysis of cellulose (Ruiz et al., 2013).

The severity factor is observed to increase with the residence time for each of the temperatures evaluated. The highest severity factor was obtained for the pretreatment of $220^{\circ} \mathrm{C}$ for $50 \mathrm{~min}$, with a value of 4.28 , now onwards referred as the most severe condition. On the other hand, 3.56 was the least severe condition evaluated, corresponding to $160{ }^{\circ} \mathrm{C}$ for $10 \mathrm{~min}$ treatment. These results are consistent with previous works of autohydrolysis pretreatment, which report severity factors ranging from 2.76 to 4.64 for temperatures between 160 and $210^{\circ} \mathrm{C}$, and residence times from 10 to $50 \mathrm{~min}$ (Aguilar et al., 2018; Romaní, Ruiz, Pereira, Domingues, \& Teixeira, 2014).

\subsubsection{Effect of hydrothermal pretreatment on the liquid phase}

The characterization of the hydrolysate obtained from the pretreatment is summarized in Table 1 . In general terms, as the severity of the pretreatment increased, the concentration of the monomeric sugars decreased, due to possible degradation of hemicellulose into acetic acid coming from acetyl bond cleavage, glucose degradation into HMF and furfural production from pentoses, which at the same time degrade into levulinic and formic acid (Li et al., 2018; Ruiz et al., 2017). The major components in the hydrolysate were hemicellulolytic derived products, being xylose the most abundant monosaccharide, with a maximum concentration of $3.715 \mathrm{~g} / \mathrm{L}$ achieved at the mildest condition, followed by arabinose which highest concentration obtained was $0.418 \mathrm{~g} / \mathrm{L}$ at $160{ }^{\circ} \mathrm{C}$ for $30 \mathrm{~min}$. It can be observed that arabinose and glucose were almost completely degraded at temperatures above $190^{\circ} \mathrm{C}$. Also, the presence of carboxylic acids was detected in the hydrolysate, namely, acetic acid, formic acid and levulinic acid, where acetic acid was the acidic degradation compound found in major proportions, with a maximum concentration of $5.524 \mathrm{~g} / \mathrm{L}$ at $220^{\circ} \mathrm{C}$ for $30 \mathrm{~min}$. Higher severity conditions produced increased hemicellulose degradation, reflected as xylose disappearance from the liquor and acetic acid content increase (its major degradation product).

On the other hand, xylo-oligosaccharides (XOS) were the component found in the highest concentration in the liquid phase, with a value of $8.366 \mathrm{~g} / \mathrm{L}$ in the pretreatment performed at $190^{\circ} \mathrm{C}$ for $10 \mathrm{~min}$. It also can be observed that conditions temperatures above $190^{\circ} \mathrm{C}$ promoted XOS complete degradation, ceasing to appear on the liquor at the most severe conditions.

\subsubsection{Effect of hydrothermal pretreatment on the solid phase}

The cellulose content in the hydrothermally pretreated solid phase, measured as glucan, showed a typical behavior of increase with the increment of the severity factor, as listed in Table 1, where the cellulose concentration increased from 27.31 to $35.36 \%$ for pretreatments carried out at $160{ }^{\circ} \mathrm{C}$, and from 38.26 to $42.93 \%$ for the temperature of $190^{\circ} \mathrm{C}$. In this work, a different tendency was observed for the assays developed at $220^{\circ} \mathrm{C}$, where cellulose content showed a reduction from 40.58 to $31.99 \%$. Ruiz et al. (2013) reported that temperatures near to $230^{\circ} \mathrm{C}$ can produce thermal cellulose degradation on hydrothermal pretreatment. Additionally, Romaní, Garrote, Alonso, and Parajó (2010), previously found cellulose yield decrease on hydrothermally pretreated Eucalyptus globulus wood at temperatures above $230^{\circ} \mathrm{C}$, which the authors attributed to partial cellulose degradation. On the other hand, Klason lignin content in the pretreated solid (see Table 1) tended to increase with the severity factor in all of the conditions evaluated, this behavior may be related to the solubilization of the hemicellulolytic phase into the liquor, which entailed lignin and cellulose to concentrate in the solid phase. The highest percentage of insoluble lignin reached was $42.95 \%$ at the most severe condition $\left(220^{\circ} \mathrm{C}\right.$ for $50 \mathrm{~min}$ ). Moreover, hemicellulose content in the solid phase, measured as xylan and arabinan, showed a diminution with the increase of the severity of the process, which confirms that this heteropolymer was being hydrolyzed into the liquid phase. It can be observed that at temperatures of $190^{\circ} \mathrm{C}$ and $220^{\circ} \mathrm{C}$ hemicellulose was completely solubilized, disappearing from the solid phase. Sabanci and Buyukkileci (2018) found hemicellulose content reduction on the solid fraction with the increment of temperature and time of liquid hot water pretreatment. They also reported almost complete solubilization of hemicellulose at $210^{\circ} \mathrm{C}$. Furthermore, Zhang et al. (2018) detected almost entire removal of hemicellulose at $190^{\circ} \mathrm{C}$, and complete degradation of hemicellulose at $210^{\circ} \mathrm{C}$ from the solid phase. Hemicellulose removal from solid phase has been reported to enhance the enzymatic saccharification (Romaní et al., 2014; Ruiz et al., 2012).

\subsubsection{Optimization of cellulose in the solid phase}

The central composite statistical analysis resulted in an optimization for cellulose content in the solid phase at $194^{\circ} \mathrm{C}$ with a residence time of $30 \mathrm{~min}$, with a predicted cellulose concentration of $43.81 \%$. The optimal conditions were experimentally evaluated to validate the model of the experimental design, obtaining a composition of $46.46 \pm 1.23 \%$ of cellulose (as glucan) and $38.86 \pm 0.28 \%$ of lignin 

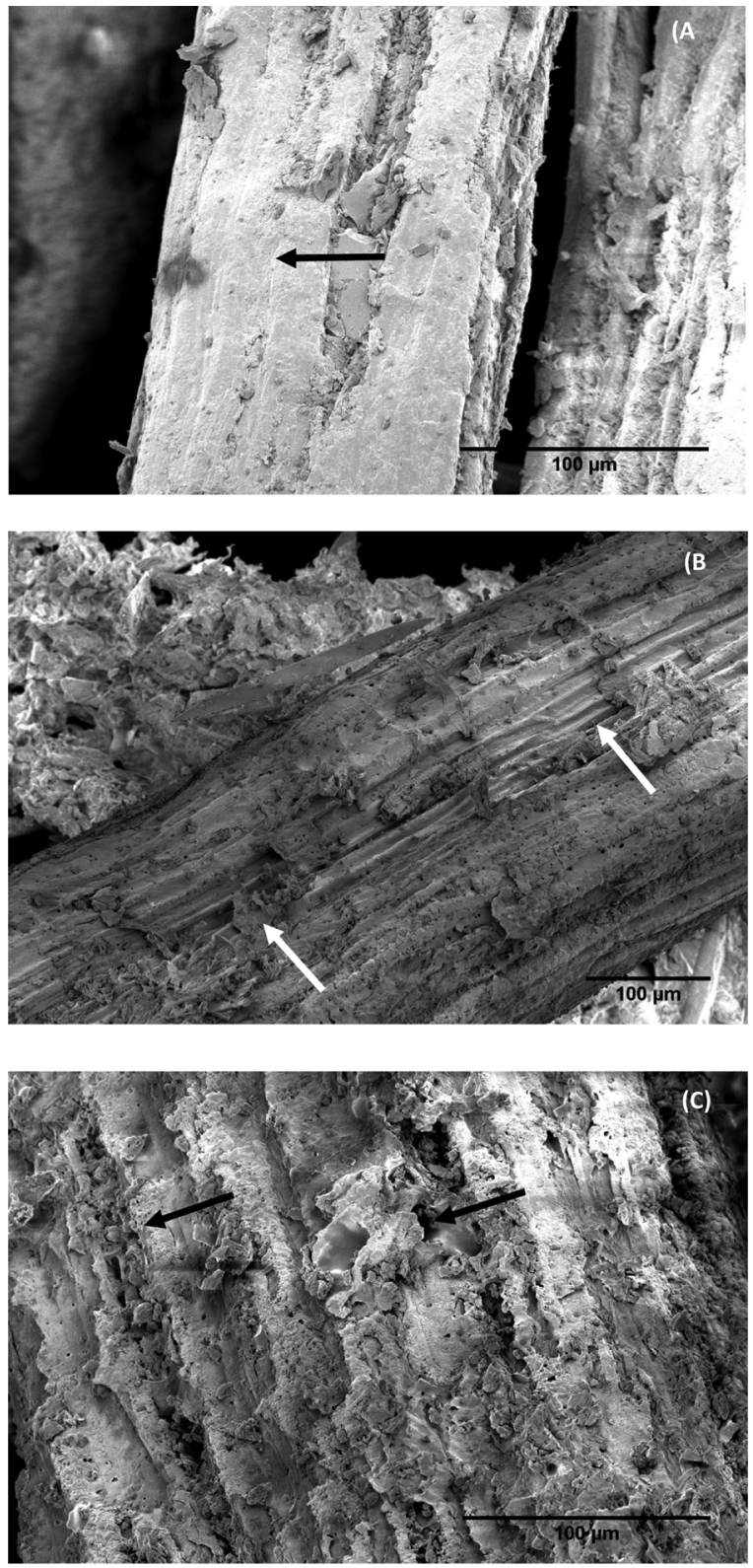

Fig. 1. SEM images of agave bagasse. (A) Untreated agave bagasse; (B) hydrothermally pretreated at optimal condition; (C) hydrothermally pretreated at the most severe condition.

in the pretreated solid, similar percentage to the predicted one for cellulose content. The severity factor with the optimal conditions resulted in a value of 3.99. Furthermore, the Analysis of variance (ANOVA) evaluated for glucan content showed that temperature and the interaction among temperature and time were significant factors in the concentration of glucan obtained in the pretreated solid fraction of agave bagasse, where the pretreatment temperature showed higher significance in the autohydrolysis process (see supplementary data).

The central composite design provided a model fitting mathematical expression to predict cellulose content in the pretreated solid fraction, as shown in Eq. (7), with a regression coefficient $\left(R^{2}\right)$ of 0.96 . Where, $T$ is the temperature of the pretreatment $\left({ }^{\circ} \mathrm{C}\right)$ and $t$ is the reaction time (min).

Cellulose $(\%)=-352.389+3.8144 T-0.00926 T^{2}+1.6484 t-0.0049 t^{2}$

$$
-0.0069 T t
$$

\subsubsection{Scanning electron microscopy}

Structural fiber differences in the AGB between the raw material and pretreated solid at the optimal condition and the most severe condition evaluated are illustrated in Fig. 1. It can be observed that the untreated biomass (Fig. 1(A)) showed a robust and ordinated structure, while the pretreated solid at the optimal conditions (Fig. 1(B)) presented a clear deconstruction of the fibers due to the morphological changes induced during the autohydrolysis. Additionally, the SEM images for the most severe pretreatment illustrated in Fig. 1(C) showed the highest structural modification on the lignocellulosic biomass, with the maximum fibers disruption.

\subsubsection{Crystallinity index}

The crystallinity index of untreated AGB calculated using Eq. (3) and the diffractograms (data not showed) was $50.34 \%$, while the $\mathrm{CrI}$ for pretreated agave bagasse at $194{ }^{\circ} \mathrm{C}$ for $30 \mathrm{~min}$ was $75.93 \%$, and the crystallinity index for the biomass hydrothermally pretreated at $220^{\circ} \mathrm{C}$ for 50 min was $81.99 \%$. The result obtained for the raw AGB is in accordance with other authors. Montiel, Hernández-Meléndez, VivaldoLima, Hernández-Luna, and Bárzana (2016) reported a crystallinity index of $\mathbf{4 5 . 9 \%}$ for untreated agave bagasse. Also, Kestur et al. (2013) reported a $\mathrm{CrI}$ for bagasse fibers of blue agave of $70 \%$ using extrusion as pretreatment. The results obtained by X-ray diffraction showed an increase on cellulose crystallinity with the pretreatment, both pretreated samples presented higher crystallinity than the raw material, which may be attributed to the removal of hemicellulose (an amorphous component) from the solid; allowing an increase on the relative amount of crystalline cellulose. Many authors have found the same increasing behavior on the crystallinity index after the pretreatment, associating it to the consumption of the non-crystalline regions (Kaschuk \& Frollini, 2018; Yang, Dai, Ding, \& Wyman, 2011).

\subsection{Enzymatic hydrolysis}

\subsubsection{Enzymatic hydrolysis in shake flasks}

First, the susceptibility of the pretreated AGB to the enzymatic attack was studied at a solid loading of $1 \%(\mathrm{w} / \mathrm{v})$ to identify the ability of the substrate to be degraded by the action of cellulases at the optimal conditions. The enzymatic hydrolysis kinetics for pretreated agave bagasse are presented in Fig. 2(A) for glucose concentration and Fig. 2(B) for saccharification yield. The pretreated substrate demonstrated to be susceptible to enzymatic depolymerization, with a cellulose conversion yield of $95.5 \%$ after $72 \mathrm{~h}$ of enzymatic hydrolysis. Aguilar et al. (2018) obtained similar results, with a maximum hydrolysis yield of $99 \%$ for solid loading of $1 \%(\mathrm{w} / \mathrm{v})$ of agave bagasse hydrothermally pretreated. It is important to highlight that regarding the pretreated AGB, the control (untreated biomass) presented $36.95 \%$ of the saccharification yield reached with the treated biomass. The results confirmed that hydrothermal pretreatment clearly improves the $\mathrm{EH}$ process by modifying the recalcitrant structure of the lignocellulosic substrate and enabling the access of the cellulolytic enzymes to cellulose. Similar data was previously reported by Ruiz et al. (2012), who reached a maximum saccharification yield of $30.36 \%$ for untreated wheat straw at a cellulose concentration of $1 \%(\mathrm{w} / \mathrm{v})$, compared to $90.88 \%$ obtained for the substrate pretreated by autohydrolysis.

The kinetics showed a typical enzymatic hydrolysis tendency, where at the beginning of the reaction, fast hydrolytic rates were obtained; however, a decreased productivity was observed over reaction time leading to a stationary phase. Zhang et al. (2010) explained this slowdown on the saccharification rate as a result of enzyme deactivation, mainly caused by non-productive adsorption of cellulases onto lignin, product inhibition, and by the presence of hemicellulose; however, in the present study, the pretreated substrate did not contain hemicellulose, therefore, cellulase-lignin linkages and feedback inhibition were considered the major factors of productivity rate drop through the catalytic reaction. Additionally, the results showed that glucose yield 

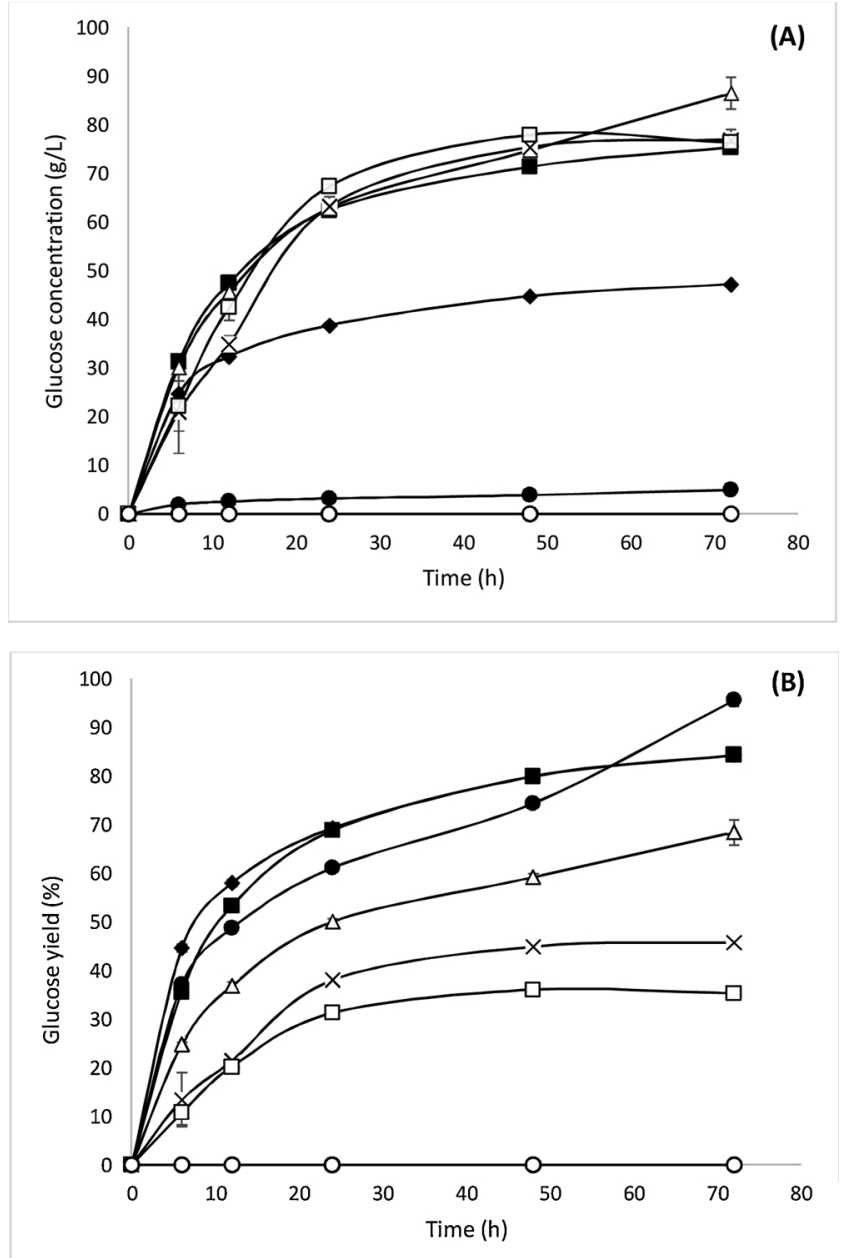

Fig. 2. Enzymatic hydrolysis kinetics in shake flasks for pretreated agave bagasse at the optimal condition. (A) Glucose concentration; (B) glucose yield. (O)

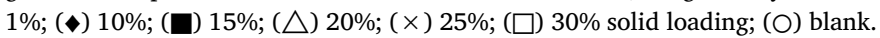

tends to decrease with the increase of the solid loading. The One-way ANOVA showed that substrate loading is a significant factor $(p \leq 0.05)$ on the glucose yield reached in the EH of pretreated AGB; while multiple means comparison test performed according to Tukey's criteria indicated that 10 and $15 \%(\mathrm{w} / \mathrm{v})$ solids loading presented no significant difference on the cellulose to glucose conversion yield achieved at $72 \mathrm{~h}$. The reduction on the saccharification efficiency has been previously reported as a result of the high viscosity of the slurry that limits the mass transfer and hinders the enzyme-substrate interactions (Pino et al., 2018). The presence of lignin is another possible factor that hinder the saccharification by acting as a physical barrier for cellulases to access cellulose, inducing non-productive linkage and adsorption of the enzyme into lignin's surface (Du et al., 2017). Furthermore, feedback inhibition has been widely reported as one of the main obstacles restricting enzymatic hydrolysis improvement at high solid concentrations (Andrić et al., 2010). The results obtained are in good agreement with previously reported investigations. Montiel et al. (2016) studied the EH of extruded blue agave bagasse at 2.5 and $20 \%(\mathrm{w} / \mathrm{v})$ substrate level, finding out a saccharification yield decreased from $96 \%$ to $73.6 \%$ with the solid level increment. The authors explained the decreasing yield behavior as a result of end-product inhibition produced by the presence of high glucose concentrations achieved through out the hydrolysis. Cara et al. (2007) stated that one of the main obstacles of enzymatic saccharification is the presence of high concentrations of glucose that inhibits cellulase enzymes. In agreement with this work, the authors observed mixing difficulties at substrate consistencies higher than $20 \%(\mathrm{w} / \mathrm{v})$ on the enzymatic hydrolysis of liquid hot water pretreated olive tree biomass. They also found decreased glucose yields as a function of increased substrate concentrations, obtaining $61 \mathrm{~g} / \mathrm{L}$ of glucose as the highest glucose concentration reached at solid consistency of $30 \%(\mathrm{w} / \mathrm{v})$ at $72 \mathrm{~h}$ of enzymatic reaction. Likewise, Battista et al. (2018) reported high viscosity of wheat straw at $20 \%$ dry matter concentration which produced stirring problems and mass transfer. Du et al. (2018) studied end-product inhibition, specifically glucose inhibition, and mass transfer limitation at high solid loadings saccharification of delignified corncob residue. The results showed that both features influenced negatively the cellulose conversion, but the authors concluded that mass transfer limitation effect was more significant than feedback inhibition.

On the other hand, according to the saccharification profiles presented in Fig. 2(A), the highest concentration of glucose was achieved at $20 \%$ solids loading, with a value of $86.55 \mathrm{~g} / \mathrm{L}$, corresponding to a glucose yield of $68.37 \%$. These results are in accordance to the reported previously by Klein-Marcuschamer, Oleskowicz-Popiel, Simmons, and Blanch (2012) who addressed that commonly, at this solid loading typical percentages of conversion of cellulose to glucose of $70 \%$ are achieved.

Furthermore, the initial saccharification rates of glucose release were $0.209,2.697,2.603,2.621,2.635$, and $2.807 \mathrm{~g} /(\mathrm{Lh})$, value that corresponds to the glucose production through reaction time and, is calculated as $d G / d t$, where $G$ is the glucose concentration and $t$ is the reaction time. It can be observed that at low solids loadings (from 1 to $10 \%$ ), the productivity increases from 0.209 to $2.697 \mathrm{~g} /(\mathrm{L} \mathrm{h})$. According to the results obtained in the present work, Ruiz et al. (2012) reported an initial hydrolysis rate of $0.47 \mathrm{~g} /(\mathrm{L} \mathrm{h})$ for hydrothermally pretreated wheat straw at $1 \%(\mathrm{w} / \mathrm{v})$ solid loading. However, the results showed that at higher solids loadings (from 10 to $30 \%(\mathrm{w} / \mathrm{v})$ ), the productivity remained relatively constant due to mass transfer limitations that retard the liquefaction of the substrate due to the high initial viscosity of the reaction slurry as a result of few free water in the medium, which delays hydrolysis rate (Montiel et al., 2016). Additionally, another important factor that may have delayed the initial hydrolysis rate is the high amount of cellobiose and glucose, which may have led to a product inhibition of cellulases, hindering the rates of cellulose saccharification (Andrić et al., 2010).

3.3.1.1. Kinetic modeling of enzymatic hydrolysis. The experimental glucose production kinetics at the different substrate loadings studied previously in Section 3.3.1 for hydrothermally pretreated AGB, were fitted to first and second order kinetic models proposed by Zhang et al. (2010). The adjustments are illustrated in Fig. 3(A)-(F) for solid concentrations of $1,10,15,20,25$ and $30 \%(\mathrm{w} / \mathrm{v})$, respectively. The fitted kinetic parameters and the correlation coefficient are summarized in Table 2. The model showed high prediction accuracy, with correlation coefficients $R^{2}$ above 0.95 . Nevertheless, contrary to the reported by Ruiz et al. (2012) and Zhang et al. (2010), who found out a better correlation of their experimental data to second order kinetic model for hydrothermally pretreated wheat straw; in this work, the experimental data for enzymatic kinetics of glucose production did not show a tendency on the adjustment to a specific order of the enzymatic deactivation model. This behavior may be related to the variety of substrate loadings evaluated in this investigation, ranging from 1 to $30 \%(\mathrm{w} / \mathrm{v})$, values way above the tested by the authors, who examined fixed solid loadings of 1 and 5\%, respectively. As can be appreciated in Fig. 3(E) and (F), corresponding to pretreated biomass at solid loadings of 25 and $30 \%(\mathrm{w} / \mathrm{v})$, the substrate concentration increase may have produced a deviation from the ideally of low concentrations assays, which caused a reduction on the saccharification efficiency and, thus a deviation on the expected kinetic curves. Moreover, the transglycosylation reaction is another potential phenomenon that may have caused the reduction in the prediction accuracy of the model to the experimental results at solid loadings above $25 \%$. The transglycosylation is a reverse reaction that consists on the conversion of glucose back to 

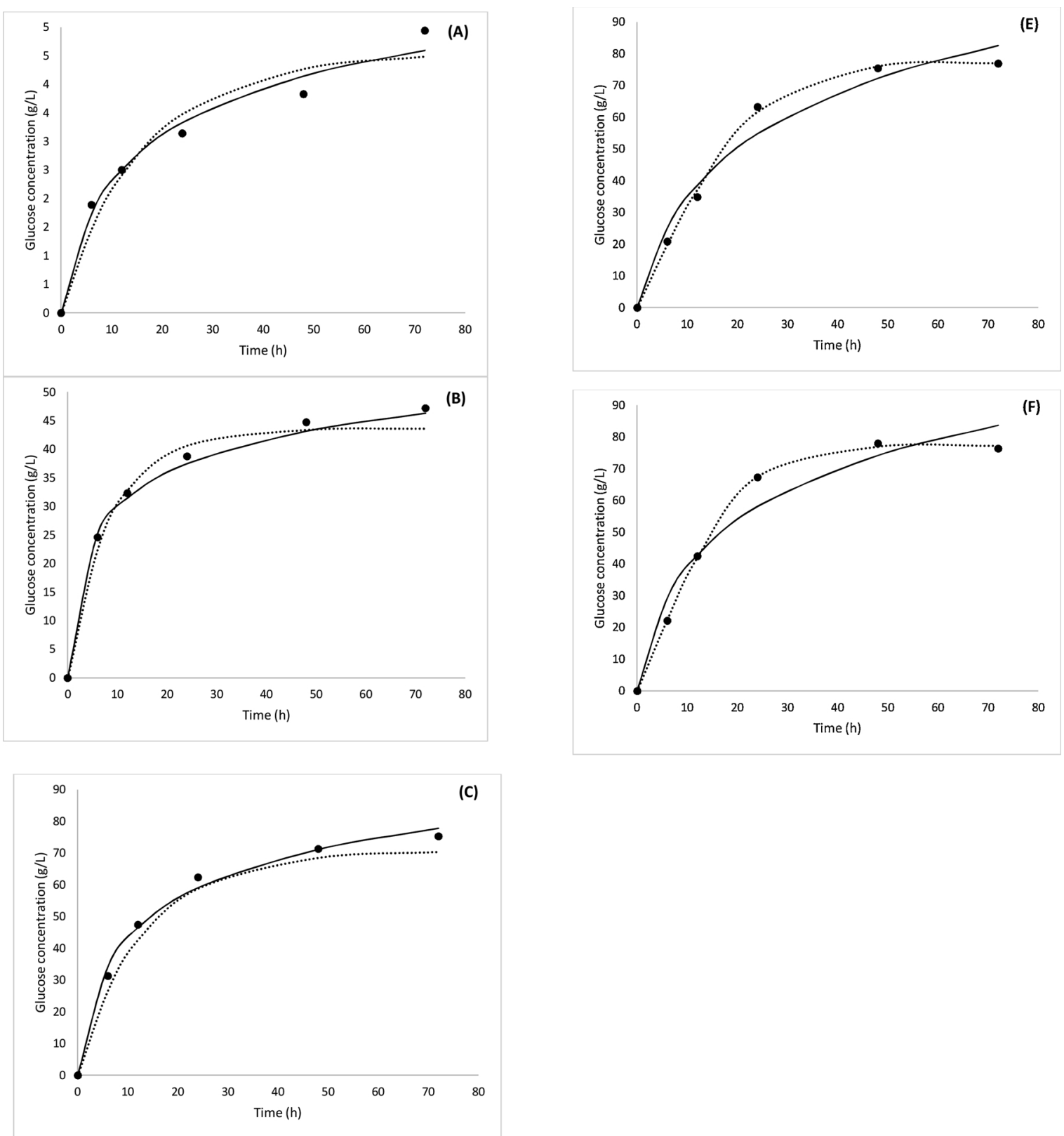

\section{)}

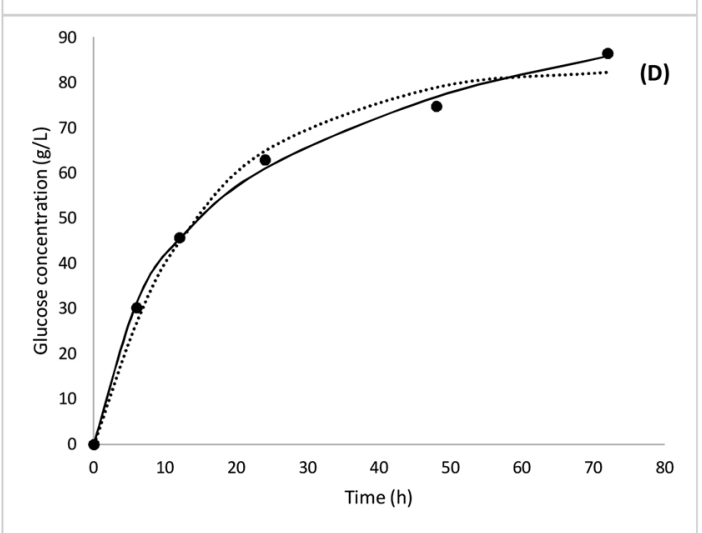

Fig. 3. Kinetic modeling for glucose concentration by cellulase deactivation model at $30 \%$ solids loading for pretreated agave bagasse. (A) $1 \%$, (B) $10 \%$, (C) $15 \%$, (D) 20\%, (E) 25\%, and (F) 30\% solid loading. (@) Experimental data; (*) modeling based on first order reaction; (-) modeling based on second order reaction.

oligosaccharides in the presence of high concentrations of glucose and cellobiose (Tsai, Morales-Rodriguez, Sin, \& Meyer, 2014). However, the model presented a good prediction fit of the experimental data, both for first and second order for each of the substrate loadings evaluated, with regression coefficients $\left(R^{2}\right)$ greater than 0.95 .

The equilibrium constants for first and second order models are 
Table 2

Fitted kinetic parameters for model of cellulase deactivation proposed by Zhang et al. (2010).

\begin{tabular}{|c|c|c|c|c|c|c|c|c|c|c|c|c|}
\hline \multirow[t]{3}{*}{ Kinetic parameter } & \multicolumn{2}{|l|}{$1 \%$} & \multicolumn{2}{|l|}{$10 \%$} & \multicolumn{2}{|l|}{$15 \%$} & \multicolumn{2}{|l|}{$20 \%$} & \multicolumn{2}{|l|}{$25 \%$} & \multicolumn{2}{|l|}{$30 \%$} \\
\hline & $1^{\circ}$ & $2^{\circ}$ & $1^{\circ}$ & $2^{\circ}$ & $1^{\circ}$ & $2^{\circ}$ & $1^{\circ}$ & $2^{\circ}$ & $1^{\circ}$ & $2^{\circ}$ & $1^{\circ}$ & $2^{\circ}$ \\
\hline & Order & Order & Order & Order & Order & Order & Order & Order & Order & Order & Order & Order \\
\hline$K_{e}$ & 101.99 & 11.81 & 102.00 & 4.39 & 102.00 & 2.53 & 102.00 & 2.50 & 0.97 & 12.90 & 0.69 & 12.22 \\
\hline$k_{2}$ & 4.76 & 0.97 & 0.83 & 0.26 & 0.37 & 0.09 & 0.20 & 0.04 & 0.01 & 0.03 & 0.01 & 0.03 \\
\hline$k_{d e 1}$ & 0.05 & - & 0.10 & - & 0.07 & - & 0.06 & - & 0.12 & - & 0.16 & - \\
\hline$k_{d e 2}$ & - & 0.40 & - & 0.49 & - & 0.22 & - & 0.13 & - & 0.02 & - & 0.04 \\
\hline$R^{2}$ & 0.95 & 0.98 & 0.99 & 1.00 & 1.00 & 0.99 & 0.99 & 1.00 & 1.00 & 0.97 & 1.00 & 0.96 \\
\hline
\end{tabular}

summarized in Table 2. The fitted kinetic parameters obtained are consistent with the reported by Ruiz et al. (2012) who applied the same model to adjust the experimental data for glucose production on wheat straw pretreated by autohydrolysis process. In the results, an evident decrease on the constant of glucose production rate $\left(k_{2}\right)$ was obtained with the increase of the solid concentration. The substrate loading of $1 \%(\mathrm{w} / \mathrm{v})$ presented the highest glucose production rate constant, while $30 \%(\mathrm{w} / \mathrm{v})$ corresponded to the lowest one. This behavior can be attributed to the greater viscosity of the cellulosic substrate at high solid concentrations, which produced mixing and diffusion difficulties and could have led to an augmented non-specific adsorption of cellulases onto lignin (Du et al., 2017).

Additionally, the retained cellulase activity was calculated according to Eq. (8), which allowed to determine the cellulase deactivation through the enzymatic hydrolysis time.

$\frac{[E]}{E_{0}}=\frac{1}{\left[E_{0}\right] k_{d e 2} t+1}$

Fig. 4 illustrates the estimation of the residual cellulase activity $\left([E] /\left[E_{0}\right]\right)$ variation through the reaction time for pretreated AGB enzymatic hydrolysis at different substrate concentrations. Cellulase enzymes demonstrated to lose most of their catalytic activity in the first's hours of the enzymatic reaction, with a continuous decrease until tending to zero. As presented in Fig. 4, cellulase activity losses above $60 \%$ were obtained in the first $6 \mathrm{~h}$ of hydrolysis, with the highest remaining enzyme activity at $1 \%(\mathrm{w} / \mathrm{v})$ solid loading and the lowest at $30 \%(\mathrm{w} / \mathrm{v})$. Substrate concentrations above $10 \%(\mathrm{w} / \mathrm{v})$ showed almost complete enzyme lose after $24 \mathrm{~h}$ of reaction, which can be associated with lower saccharification rates and subsequently, slower glucose production (see Section 3.3.1), as a consequence of cellulases deactivation by enzyme-substrate non-productive binding and end-product inhibition. It has been stated that the saccharification productivity is directly related to the amount of enzymes adsorbed (Ma et al., 2008).

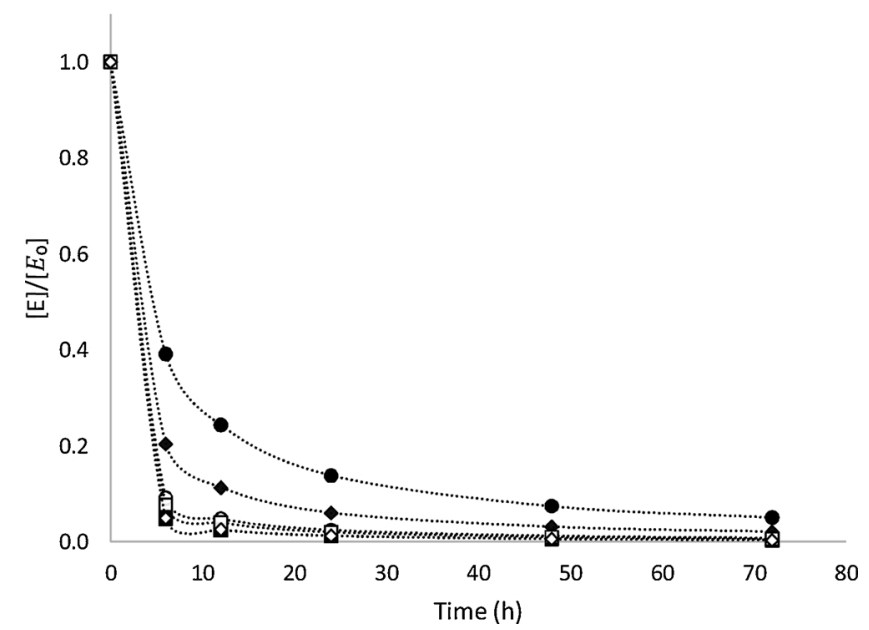

Fig. 4. Effect of solid loading on residual cellulase activity for pretreated AGB.

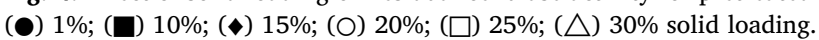

Zhang et al. (2010) reported cellulase activity losses above 30\% (w/v) in the first hour of enzymatic saccharification of steam exploded wheat straw, holding less than $20 \%(\mathrm{w} / \mathrm{v})$ enzyme activity retained at $12 \mathrm{~h}$. The authors attributed the activity lose to enzyme deactivation mainly to non-specific adsorption. Likewise, Gan, Allen, and Taylor (2003) developed a mathematical model to simulate the kinetic interactions among the substrate, enzyme and products on the enzymatic hydrolysis of cellulose. The kinetic model, in accordance to their experimental data, showed a high saccharification rate at the beginning of the reaction followed by an accelerated loss of enzyme catalytic power through the reaction time, undergoing a decrease of approximately $60 \%$ of the initial activity of the soluble enzyme in less than $4 \mathrm{~h}$ of reaction. The enzyme deactivation was attributed to the unspecific adsorption of cellulases and product inhibition. Furthermore, Ko, Ximenes, Kim, and Ladisch (2015) studied the adsorption of cellulases onto isolated lignin preparations obtained from hydrothermally pretreated hardwoods. The results showed that, in the cellulases complex, $\beta$-glucosidase was the enzyme more affected by non-productive adsorption onto lignin, undergoing activity losses from 82 to $98 \%$, whilst exoglucanase and endoglucanases presented residual activities between 50 and $60 \%$. The deactivation pattern obtained, allowed further comprehension of the catalytic mechanism; concluding that the almost complete deactivation of $\beta$-glucosidase by adsorption onto lignin, led to an accumulation of cellobiose, which has been demonstrated to inhibit endoglucanases and consequently, halted the enzymatic saccharification by excess of cellobiose and glucose; hence non-specific cellulase adsorption onto lignin and product inhibition were directly associated. Accordingly, the efficiency of the catalytic action of cellulase enzymes is reduced in the first few hours of the enzymatic saccharification, which is directly related to the fast-initial hydrolysis rate, followed by a drastic drop on the glucose production throughout the reaction, presumably caused by enzymelignin adsorption and feedback inhibition.

\subsubsection{Horizontal bioreactor operation for enzymatic hydrolysis at high solid loading}

3.3.2.1. Batch-mode in the horizontal bioreactor. The agitation system of the bioreactor designed allowed to achieve a faster liquefaction of the slurry than obtained in the shake flasks assays at high solid loadings, which was demonstrated by a drastically decreased in the initial viscosity of the pretreated biomass. It has been stated that at solid concentrations above $25 \%(\mathrm{w} / \mathrm{v})$ dry matter, almost all the water is entrapped at the cell wall of the plant, which difficult the diffusion process . Fig. 5(A) shows the pretreated agave bagasse at the beginning of the enzymatic hydrolysis inside the bioreactor, it can be appreciated that there was no free water in the reaction medium, and that the material presented a paste-like appearance due to high concentration of insoluble matter, which commonly hinders the mass transfer between the enzyme and the substrate. Along the reaction time, the material was liquefied, modifying its structure from solid to liquid as a result of biomass structure break down. Fig. 5(B) illustrates the liquefied slurry obtained after $72 \mathrm{~h}$ of the enzymatic reaction in the bioreactor, showing a clear reduction on the viscosity of the material. According to Du et al. (2014), the viscosity changes during the enzymatic saccharification are 

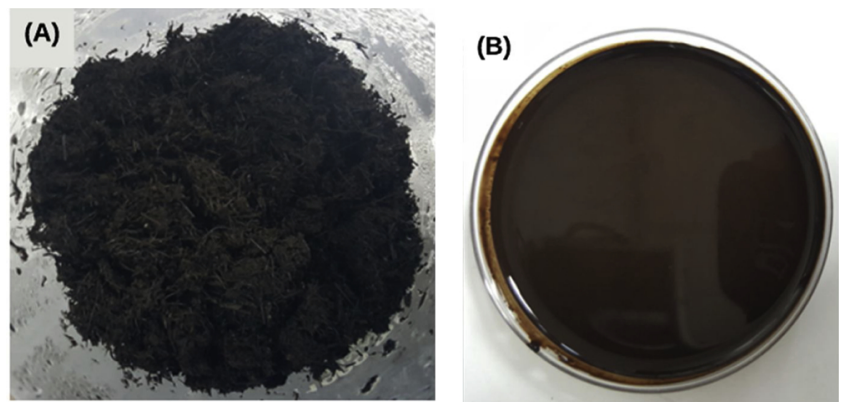

Fig. 5. Liquefaction of agave bagasse after enzymatic hydrolysis on designed bioreactor. (A) Pretreated agave bagasse before saccharification; (B) liquefied agave bagasse after enzymatic hydrolysis in the bioreactor.

the result of a variety of phenomena, including the hydrolysis of different chemical linkages, as well as the diminution of water binding capacity in the material and the reduction in the concentration of water insoluble solids. Furthermore, a reaction volume reduction was observed from the beginning of the saccharification until elapsed the $72 \mathrm{~h}$ of reaction. Jørgensen et al. (2007) also described volume diminution on the enzymatic hydrolysis of steam pretreated wheat straw on a horizontal bioreactor at $25 \%$ (w/ w) substrate concentration and related this phenomenon to the modification of the biomass structure and the viscosity drop throughout the enzymatic reaction.

The glucose kinetics for the $\mathrm{EH}$ assays carried out in the bioreactor are presented in Fig. 6 . The results showed an improvement in the cellulose conversion yield compared with the assays carried out in shake flasks at high solid loadings (please see Section 3.3.1), which can be ascribed to a better mixing performance that led to a more efficient biomass digestion and greater final glucose yields. Roche, Dibble, and Stickel (2009) associated the initial mixing efficiency with the improved cellulolytic enzymes distribution throughout the substrate. The results showed the most remarkable enhancement in the assay at $25 \%$ $(\mathrm{w} / \mathrm{v})$ insoluble matter, reaching a glucose titer of $195.60 \mathrm{~g} / \mathrm{L}$ at $72 \mathrm{~h}$ of reaction, equivalent to a cellulose conversion yield of $97.99 \%$, which is 2.14 times higher than the one achieved on shake flasks (45.72\%). It is important to highlight that elapsed $6 \mathrm{~h}$ of reaction, the glucose yield on the bioreactor had already attained $53.03 \%$ of cellulose conversion, value higher than the obtained at $72 \mathrm{~h}$ on shake flasks. Dasari et al. (2009) designed a horizontal scraped surface bioreactor for saccharification process at high solid loadings, in which a cellulose conversion of $70 \%$ was achieved at $25 \%(\mathrm{w} / \mathrm{w})$ substrate loading of dilute acid pretreated corn stover.

Furthermore, Fig. 6 shows that the increase of the substrate loading to $30 \%(\mathrm{w} / \mathrm{v})$, produced a decrease on glucose concentration to $124.01 \mathrm{~g} / \mathrm{L}$, corresponding to a saccharification yield of $47.64 \%$, which represents an improvement of $35.19 \%$ compared to the shake flask experiments. Even though an enhancement was observed, it was lower than the one obtained for $25 \%(\mathrm{w} / \mathrm{v})$ substrate loading, which may be related to end-product inhibition. Caspeta et al. (2014), reported glucose concentrations up to $225 \mathrm{~g} / \mathrm{L}$ at $30 \%(\mathrm{w} / \mathrm{v})$ substrate level; even though, this result is higher than the maximum concentration achieved in this work. It is important to highlight that the sugars final concentration depend on the initial glucan concentration in the raw material, which the researchers reported as $38.6 \%$ total dry weight, value above the obtained in the AGB used in this project (25.67\%). Unfortunately, the authors did not report the glucose yield reached in their investigation.

The productivities of glucose release achieved on the bioreactor were $10.71,4.21,7.79$ and $7.23 \mathrm{~g} / \mathrm{L} \mathrm{h}$ for fixed $25 \%(\mathrm{w} / \mathrm{v})$, fixed $30 \%$ $(\mathrm{w} / \mathrm{v})$ solid loading, fed-batch strategy (1) and (2), respectively. The highest productivity achieved was at $25 \%(\mathrm{w} / \mathrm{v})$ fixed solids loading, which also was the substrate loading that produced the highest

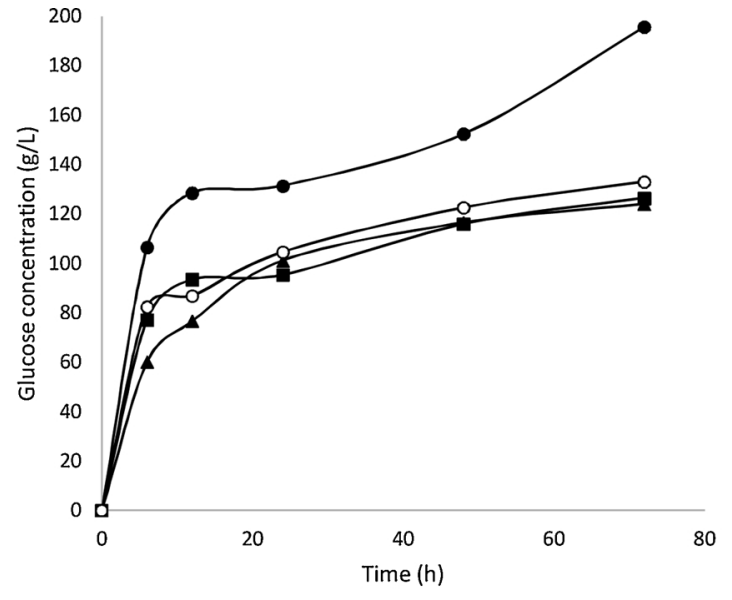

(A)

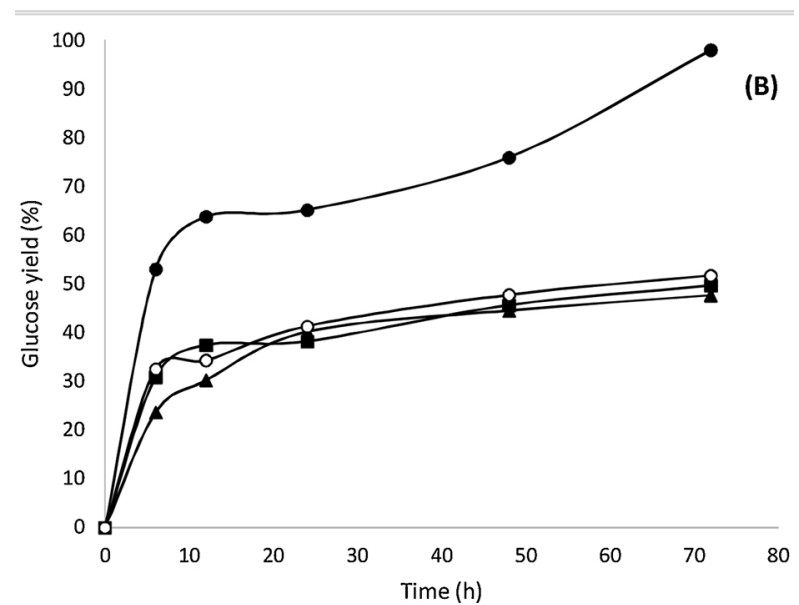

Fig. 6. Enzymatic hydrolysis kinetics in the designed bioreactor. (A) Glucose

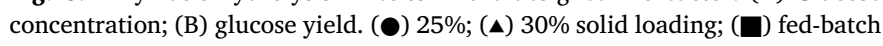
(1); (O) fed-batch (2).

cellulose conversion. However, when the solid loading increased to $30 \%(\mathrm{w} / \mathrm{v})$, the productivity decreased to $4.21 \mathrm{~g} /(\mathrm{L} \mathrm{h})$, which can be related the greater insoluble matter concentration that might delay the liquefaction of the reaction mixture, as shown in Fig. 6. It is important to highlight that the productivities reached on the bioreactor designed were much higher than the ones achieved on the shaking flasks assays (ranged from 0.209 to $2.807 \mathrm{~g} / \mathrm{Lh}$ ), which proves better liquefaction level due to enhanced mixing effect provided by the agitation system designed.

3.3.2.2. Fed-batch strategies in the horizontal bioreactor. The fed-batch mode operation of bioreactors for $\mathrm{EH}$ at high solid loading has been proposed as a viable alternative to overcome rheology limitations of the reaction mixture by reducing the initial viscosity and preventing mixing difficulties (Chen \& Liu, 2016). The EH kinetics for the two fed-batch strategies at $30 \%(\mathrm{w} / \mathrm{v})$ solid loading evaluated are illustrated in Fig. 6(A) and (B) for glucose concentration and saccharification yields, respectively. It can be observed in the kinetics that slight glucose production and yield enhancement was achieved with fedbatch mode. The strategy (1) produced an improvement of $4.20 \%$ on the cellulose conversion, regarding the batch assay at $30 \%(\mathrm{w} / \mathrm{v})$ dry matter; while strategy (2) generated an improvement of $8.52 \%$. The results demonstrated that the fed-batch mode produced a betterment of the enzymatic hydrolysis at high solid loadings. Du et al. (2017) studied substrate feeding and simultaneous substrate and enzyme feeding at solid concentrations of 10,15 and $20 \%(w / v)$ dry matter. The authors reported a cellulose conversion enhancement with the solid loading increment. Corrêa, Badino, and Cruz (2016) reached an energy 
consumption reduction of $52 \%$ using fed-batch strategies on the enzymatic saccharification of steam pretreated sugarcane on a stirred tank bioreactor with two Elephant Ear impellers. On the other hand, Sugiharto et al. (2016) stated that fed-batch mode can reduce cellulase inhibition by non-productive enzyme binding to lignin. The researchers found out that feed-batch strategy presented a positive effect on enzymatic hydrolysis of steam pretreated empty fruit bunch at $25 \%$ $(\mathrm{w} / \mathrm{v})$ solid loading. This phenomenon was explained by enzyme deactivation decrease by enzyme-lignin contact, considering that in batch processes, all the enzymes are fed at the beginning of the reaction, which might produce greater enzyme binding to lignin than if the enzymes are feed proportionally throughout the saccharification.

Moreover, the results showed that the productivities of fed-batch strategies (1) and (2) were similar, because the initial substrate concentration of both assays was $20 \%(\mathrm{w} / \mathrm{v})$. Additionally, their productivity values were intermediate between the productivity of the experiments at batch mode with solid loadings of 25 and $30 \%(w / v)$. However, the productivity of the fed-batch mode was expected to be lower than the ones achieved at the batch mode experiments, due to lower initial concentration. This behavior might be attributed to possible glucose dilution due to substrate and enzyme feeding at $12 \mathrm{~h}$ of reaction.

\section{Conclusions}

Hydrothermal pretreatment is an efficient method for lignocellulosic biomass fractionation, producing a cellulose rich solid with high susceptibility to enzymatic attack. Substrate loading increase demonstrated to negatively affect the saccharification efficiency, mainly due to mass transfer limitations. The horizontal bioreactor designed provided improved mixing efficiency at high solid loadings, enhancing biomass liquefaction and cellulose conversion, with glucose production yields up to $97.99 \%$. Cellulases lose more than $60 \%$ of their initial activity in the first 6 hours of catalytic reaction, which is directly related to the fast-initial hydrolysis rate, followed by a drastic drop on the glucose production throughout the reaction.

\section{Acknowledgements}

This project was funded by the Secretary of Public Education of Mexico - Mexican Science and Technology Council (SEP-CONACYT) with the Basic Science Project-2015-01 (Ref. 254808). Marcela Sofía Pino also thanks the National Council for Science and Technology (CONACYT, Mexico) for her Master Fellowship support (grant number: 611312/452636), and Dr. Michele Michelin thanks the Portuguese Foundation for Science and Technology (FCT) for her postdoctoral fellowship (SFRH/BPD/100786/2014).

\section{Appendix A. Supplementary data}

Supplementary data associated with this article can be found, in the online version, at https://doi.org/10.1016/j.carbpol.2019.01.111.

\section{References}

Adney, B., \& Nrel, J. B. (1996). Measurement of cellulase activities laboratory analytical procedure (LAP) (issue date: 08.12.96).

Aguilar, D. L., Rodríguez-Jasso, R. M., Zanuso, E., de Rodríguez, D. J., Amaya-Delgado, L., Sanchez, A., et al. (2018). Scale-up and evaluation of hydrothermal pretreatment in isothermal and non-isothermal regimen for bioethanol production using agave bagasse. Bioresource Technology, 263, 112-119.

Andrić, P., Meyer, A. S., Jensen, P. A., \& Dam-Johansen, K. (2010). Reactor design for minimizing product inhibition during enzymatic lignocellulose hydrolysis: I. Significance and mechanism of cellobiose and glucose inhibition on cellulolytic enzymes. Biotechnology Advances, 28, 308-324.

Cara, C., Moya, M., Ballesteros, I., Negro, M. J., González, A., \& Ruiz, E. (2007). Influence of solid loading on enzymatic hydrolysis of steam exploded or liquid hot water pretreated olive tree biomass. Process Biochemistry, 42, 1003-1009.

Caspeta, L., Caro-Bermúdez, M. A., Ponce-Noyola, T., \& Martinez, A. (2014). Enzymatic hydrolysis at high-solids loadings for the conversion of agave bagasse to fuel ethanol. Applied Energy, 113, 277-286.

Chen, H.-Z., \& Liu, Z.-H. (2016). Enzymatic hydrolysis of lignocellulosic biomass from low to high solids loading. Engineering in Life Sciences, 1-11.

Chornet, E., \& Overend, R. P. (2017). How the severity factor in biomass hydrolysis came about. In H.A, M. H. Ruiz, H. L. Thomsen, \& H. L. Trajano (Eds.). Hydrothermal processing in biorefineries (pp. 1-3). Cham: Springer.

Consejo Regulador del Tequila. Información Estadística. Consum Agave Para Tequila y Tequila 100\% Agave 2018. https://www.crt.org.mx/EstadisticasCRTweb/ (accessed 05.07.18).

Corrêa, L. J., Badino, A. C., \& Cruz, A. J. (2016). Power consumption evaluation of different fed-batch strategies for enzymatic hydrolysis of sugarcane bagasse. Bioprocess and Biosystems Engineering, 39, 825-833.

Dasari, R. K., Dunaway, K., \& Berson, R. E. (2009). A scraped surface bioreactor for enzymatic saccharification of pretreated corn stover slurries. Energy and Fuels, 23, 492-497.

Davis, S. C., Dohleman, F. G., \& Long, S. P. (2011). The global potential for agave as a biofuel feedstock. Global Change Biology Bioenergy, 3, 68-78.

Dowe, N., \& McMillan, J. (2008). SSF experimental protocols—Lignocellulosic biomass hydrolysis and fermentation laboratory analytical procedure (LAP).

Du, J., Cao, Y., Liu, G., Zhao, J., Li, X., \& Qu, Y. (2017). Identifying and overcoming the effect of mass transfer limitation on decreased yield in enzymatic hydrolysis of lignocellulose at high solid concentrations. Bioresource Technology, 229, 88-95.

Du, J., Zhang, F., Li, Y., Zhang, H., Liang, J., Zheng, H., et al. (2014). Enzymatic liquefaction and saccharification of pretreated corn stover at high-solids concentrations in a horizontal rotating bioreactor. Bioprocess and Biosystems Engineering, 37, 173-181.

Gan, Q., Allen, S. J., \& Taylor, G. (2003). Kinetic dynamics in heterogeneous enzymatic hydrolysis of cellulose: An overview, an experimental study and mathematical modelling. Process Biochemistry, 38, 1003-1018.

Kaschuk, J. J., \& Frollini, E. (2018). Effects of average molar weight, crystallinity, and hemicelluoses content on the enzymatic hydrolysis of sisal pulp, filter paper, and microcrystalline cellulose. Industrial Crops and Products, 115, 280-289.

Kestur, G. S., Flores-Sahagun, T. H. S., Dos Santos, L. P., Dos Santos, J., Mazzaro, I., \& Mikowski, A. (2013). Characterization of blue agave bagasse fibers of Mexico. Composites Part A: Applied Science and Manufacturing, 45, 153-161.

Klein-Marcuschamer, D., Oleskowicz-Popiel, P., Simmons, B. A., \& Blanch, H. W. (2012) The challenge of enzyme cost in the production of lignocellulosic biofuels. Biotechnology and Bioengineering, 109, 1083-1087.

Ko, J. K., Ximenes, E., Kim, Y., \& Ladisch, M. R. (2015). Adsorption of enzyme onto lignin of liquid hot water pretreated hardwoods. Biotechnology and Bioengineering, 112, $447-456$.

Li, H. Y., Wang, B., Wen, J. L., Cao, X. F., Sun, S. N., \& Sun, R. C. (2018). Availability of four energy crops assessing by the enzymatic hydrolysis and structural features of lignin before and after hydrothermal treatment. Energy Conversion and Management, 155, 58-67.

Ma, A., Hu, Q., Qu, Y., Bai, Z., Liu, W., \& Zhuang, G. (2008). The enzymatic hydrolysis rate of cellulose decreases with irreversible adsorption of cellobiohydrolase I. Enzyme and Microbial Technology, 42, 543-547.

Montiel, C., Hernández-Meléndez, O., Vivaldo-Lima, E., Hernández-Luna, M., \& Bárzana, E. (2016). Enhanced bioethanol Production from blue agave bagasse in a combined extrusion-saccharification process. Bioenergy Research, 9, 1005-1014.

Overend, R. P., Chornet, E., \& Gascoigne, J. A. (1987). Fractionation of lignocellulosics by steam-aqueous pretreatments (Discussion). Philosophical Transactions of the Royal Society of London. Series A, Mathematical and Physical Sciences, 321, 523-536.

Pino, M. S., Rodríguez-Jasso, R. M., Michelin, M., Flores-Gallegos, A. C., MoralesRodriguez, R., Teixeira, J. A., et al. (2018). Bioreactor design for enzymatic hydrolysis of biomass under the biorefinery concept. Chemical Engineering Journal, 347, $119-136$.

Roche, C. M., Dibble, C. J., \& Stickel, J. J. (2009). Laboratory-scale method for enzymatic saccharification of lignocellulosic biomass at high-solids loadings. Biotechnology for Biofuels, 2, 28.

Romaní, A., Garrote, G., Alonso, J. L., \& Parajó, J. C. (2010). Bioethanol production from hydrothermally pretreated Eucalyptus globulus wood. Bioresource Technology, 101, $8706-8712$.

Romaní, A., Ruiz, H. A., Pereira, F. B., Domingues, L., \& Teixeira, J. A. (2014). Effect of hemicellulose liquid phase on the enzymatic hydrolysis of autohydrolyzed Eucalyptus globulus wood. Biomass Conversion and Biorefinery, 4, 77-86.

Ruiz, H. A., Rodríguez-Jasso, R. M., Fernandes, B. D., Vicente, A. A., \& Teixeira, J. A. (2013). Hydrothermal processing, as an alternative for upgrading agriculture residues and marine biomass according to the biorefinery concept: A review. Renewable \& Sustainable Energy Reviews, 21, 35-51.

Ruiz, H. A., Thomsen, M. H., \& Trajano, H. L. (2017). Hydrothermal processing in biorefineries. Cham, Switzerland: Springer International Publishing.

Ruiz, H. A., Vicente, A. A., \& Teixeira, J. A. (2012). Kinetic modeling of enzymatic saccharification using wheat straw pretreated under autohydrolysis and organosolv process. Industrial Crops and Products, 36, 100-107.

Sabanci, K., \& Buyukkileci, A. O. (2018). Comparison of liquid hot water, very dilute acid and alkali treatments for enhancing enzymatic digestibility of hazelnut tree pruning residues. Bioresource Technology, 261, 158-165.

Segal, L., Creely, J. J., Martin, A. E., \& Conrad, C. M. (1959). An empirical method for estimating the degree of crystallinity of native cellulose using the X-Ray diffractometer. Textile Research Journal, 29, 786-794.

Sluiter, A., Hames, B., Ruiz, R., Scarlata, C., Sluiter, J., \& Templeton, D. (2012). Determination of structural carbohydrates and lignin in biomass determination of structural carbohydrates and lignin in biomass. NREL/TP-510-42618.

Sluiter, A., Hames, R., Ruiz, R., Scarlata, C., Sluiter, J., \& Templeton, D. (2008a). 
Determination of ash in biomass - NREL/TP-510-42622. NREL analytical procedure. National Renewable Energy Laboratory.

Sluiter, A., Ruiz, R., Scarlata, C., Sluiter, J., \& Templeton, D. (2008b). Determination of extractives in biomass - NREL/TP-510-42619. NREL analytical procedure. National Renewable Energy Laboratory.

Sugiharto, C. Y. E., Harimawan, A., Kresnowati, M. T. A. P., Purwadi, R., Andry, Fitriana, H. N., et al. (2016). Bioresource technology enzyme feeding strategies for better fedbatch enzymatic hydrolysis of empty fruit bunch. Bioresource Technology, 207, 175-179.

Tsai, C. T., Morales-Rodriguez, R., Sin, G., \& Meyer, A. S. (2014). A dynamic model for cellulosic biomass hydrolysis: A comprehensive analysis and validation of hydrolysis and product inhibition mechanisms. Applied Biochemistry and Biotechnology, 172, 2815-2837.

Velázquez-Valadez, U., Farías-Sánchez, J. C., Vargas-Santillán, A., \& Castro-Montoya, A. J. (2016). Tequilana weber agave bagasse enzymatic hydrolysis for the production of fermentable sugars: Oxidative-alkaline pretreatment and kinetic modeling. Bioenergy
Research, 9, 998-1004.

Wyman, C. E., Cai, C. M., \& Kumar, R. (2019). Bioethanol from lignocellulosic biomass. In M. Kaltschmitt (Ed.). Energy from organic materials (biomass) (pp. 997-1022). New York: Springer Nature.

Yang, B., Dai, Z., Ding, S.-Y., \& Wyman, C. E. (2011). Enzymatic hydrolysis of cellulosic biomass. Biofuels, 2, 421-449.

Yang, L., Lu, M., Carl, S., Mayer, J. A., Cushman, J. C., Tian, E., et al. (2015). Biomas characterization of agave and opuntia as potential biofuel feedstocks. Biomass and Bioenergy, 76, 43-53.

Zhang, H., Li, J., Huang, G., Yang, Z., \& Han, L. (2018). Understanding the synergistic effect and the main factors influencing the enzymatic hydrolyzability of corn stover at low enzyme loading by hydrothermal and/or ultrafine grinding pretreatment. Bioresource Technology, 264, 327-334.

Zhang, Y., Xu, J. L., Xu, H. J., Yuan, Z. H., \& Guo, Y. (2010). Cellulase deactivation based kinetic modeling of enzymatic hydrolysis of steam-exploded wheat straw. Bioresource Technology, 101, 8261-8266. 